\title{
Both high and low doses of cocaine derail normal maternal caregiving - lessons from the laboratory rat
}

\author{
Joan I. Morrell*, Julia C. Basso and Mariana Pereira \\ Center for Molecular and Behavioral Neuroscience, Rutgers - The State University of New Jersey, Newark, NJ, USA \\ *Correspondence: jmorrell@andromeda.rutgers.edu
}

The grave consequences of cocaine dependency and addiction for the individual are widely understood. In parents such conditions can have a particularly tragic impact since cocaine has great potential for impairing a parent's ability to properly care for their children with lifelong consequences for both the children and parent. Understanding the impact of cocaine on human parental behavior is dauntingly complex as its abuse can cooccur with abuse of other drugs and with a variety of biological and societal factors (Chasnoff, 1987, 1988; Oro and Dixon, 1987; Frank et al., 1988) that confound our understanding of the impact of the drug itself. Less considered in examining the impact of cocaine on human parental behavior is the fact that within the human population, the number of people who engage in occasional or recreational use of substances with abuse potential, including cocaine, is much larger than the number of people who are diagnosed clinically with substance dependency or addiction (Warner et al., 1995; SAMHSA, 2001-2003; O'Brien and Anthony, 2005). Since this is the case for all age groups including women of reproductive age, we speculate that the population in which cocaine could affect the care of children is larger than the population of those who have progressed to the state of cocaine dependency and addiction.

Considering that human parenting behavior has both biological roots as well as cultural and learned features is helpful in addressing the complex issue of the impact of cocaine on parenting experimentally. Further, parental behavior has both outwardly visible caregiving activities apparent in the interaction of the parent with their offspring and the underlying processes of parental motivation, which begins antecedent to caregiving and continues throughout parent-offspring interaction. The fundamental biological components of human parenting are generated by genetic and central nervous system processes very much in common with all mammals. These processes normally lead all parents to allocate a substantial proportion of time and energy to caregiving for the young in a manner that is relevant for their species. In humans, this substantial allocation of parental resources occurs over prolonged periods of time and includes the influences of cultural and "sentient" influences unique to humans that then presumably interact with the outcomes of these fundamental biological processes yielding human parental behavior.

Laboratory animal models of parental behavior provide a reductionist, mechanistic, and ultimately controllable and simplified model that offers the possibility of uncovering the CNS processes of normal parental behavior, thus allowing determination of how cocaine may derail it. Animal models of parental behavior rely on the operational definition of parental behavior in a species-specific framework. The largest and most detailed literature on the biology underlying parental behavior has been generated using the laboratory rat model (Rosenblatt et al., 1979; Numan and Insel, 2003; Lonstein and Morrell, 2007). In rats, only the postpartum female cares for the pups, hence the term maternal behavior. The rat model of maternal behavior is commonly used with the unstated working hypothesis that it has construct validity for general CNS processes that underlie normal maternal behavior in humans, just as the rat models of drug dependency are hypothesized to have such validity for human drug dependency (Epstein et al., 2006). Both models are commonly considered to have strong face validity for the human condition.

Many studies, including our earliest study (Vernotica et al., 1996), have examined the effects of cocaine on the caregiving aspects of maternal behavior in the rat, including pup retrieving, nursing, nest building, maternal pup-grooming, that consists of anogenital and corporal licking, and maternal aggression (Zimmerberg and Gray, 1992; Johns et al., 1994, 1998; Kinsley et al., 1994). These studies use dosages and treatment regimes of cocaine that model, to some extent, drug use patterns and dosages reported in the dependent human user. Commonly used dosages in these studies result in peak plasma levels of approximately $200-900 \mathrm{ng} / \mathrm{ml}$ of cocaine (10-40 mg/kg injected), closely resembling plasma levels reported for the dependent human user, and associated with subjective reports of "feeling high" (Javaid et al., 1978; Smith et al., 1989).

Collectively, these studies in rats leave little doubt that plasma levels of cocaine above $200 \mathrm{ng} / \mathrm{ml}$ have profound negative effects on all aspects of maternal caregiving, resulting in the complete cessation of all pup-directed behaviors. Once cocaine leaves the blood, most of the components of maternal caregiving return (Zimmerberg and Gray, 1992; Johns et al., 1994, 1998; Kinsley et al., 1994). However, in females subjected to prolonged cocaine exposure during pregnancy, certain effects on postpartum maternal behavioral can be found in the females long after their cocaine treatment has ended. Additionally in offspring, transgenerational effects independent of their exposure to cocaine can be seen (Johns et al., 1994, 2005; McMurray et al., 2008).

The profound effects of these doses of cocaine on pup-caregiving by the postpartum female rat underscores the importance of avoiding cocaine if maternal caregiving is to remain intact and to ensure that the normally large allocation of time and energy by the mother in caregiving continues. This leads us to the conclusion that it is crucial to understand the motivational processes at work during choices among stimuli by the postpartum female rats. Even for humans, this may have real world importance as parents care for their offspring in a world full of other choices for their time and attention, including the choice of highly salient stimuli such as cocaine. 
Our preclinical model focuses on the processes of motivated choices during the initial or acute stages of cocaine exposure, an aspect of cocaine exposure that is generally less studied in behavioral examinations of the impact of cocaine in the rat. This initial sampling period may be important as cocaine dependency in humans can begin with "recreational" or casual sampling which usually involves fewer and lower doses of cocaine than those of the dependent user, with a considerable temporal interval before the levels of use reach those found in dependent human users (Gawin, 1991). Further, the demographic information suggests that many cocaine users engage in sampling or occasional use of cocaine and may continue to use the drug without progression to abuse levels. We speculate that among this considerable number of occasional users are parents.

Studies on the expression of maternal caregiving in rats are commonly thought to be examining motivated behavior as they look at the approach and sustained effort of the postpartum female in the pup-caregiving process. Hence we examine the influence of cocaine on the unconditioned responses of postpartum females with their pups, and consider that we are examining both motivational and stimulus interaction aspects of the behavioral sequence. However, difficulties arise in distinguishing motivational from motor processes when stimulus interaction is ongoing, making it challenging to study the neural substrate of motivation. This is particularly limiting in the case of interaction with the pup stimulus which occurs almost continuously once the female contacts a pup. Further complications emerge when maternal caregiving is influenced by the ongoing impact of a pharmacological stimulus, i.e., when cocaine is in the blood.

One experimental approach that avoids these difficulties and allows separate examination of the stimulus approach phase of motivation versus the phase of motivated interaction with the stimulus is the conditioned place preference (CPP) procedure (Berridge, 2004, 2007; Tzschentke, 2007). Thus in addition to our experiments on the influence of cocaine on the unconditioned responses of females to their pups, we originated a concurrent pup/cocaine-CPP choice task to explore the relative incentive salience of cocaine administration versus maternal interaction with pups in the postpartum female (Mattson et al., 2001, 2003). We are examining the neural substrates at work during this CPP choice task and have determined that subregions of the medial prefrontal cortex, the medial preoptic area, and the ventral tegmental area underlie the choice of pup-versus cocaine-conditioned incentives (Mattson and Morrell, 2005; Seip and Morrell, 2007; Pereira and Morrell, 2010a,b). As our purpose here is to discuss some findings from our conjoint experiments on the effects of cocaine on unconditioned aspects of maternal caregiving, the reader is referred to our primary papers and reviews of this CPP work (Pereira et al., 2008; Seip and Morrell, 2009; Pereira and Morrell, 2010a,b, in preparation).

Conjoint with our motivational analysis using the CPP choice task, we examine the effect of cocaine on the expression of maternal behavior, i.e., the effect of cocaine on the unconditioned responses of the female to the pup, and measure blood levels of cocaine in the postpartum female at behaviorally key time points. We have also used the CPP procedure in a more conventional construction to determine the relative incentive salience of various cocaine doses compared to a more neutral stimulus, a saline injection. From these three data sets (Figures 1A-C), we have achieved an overview of the relationship of blood levels of cocaine, the incentive salience of these various plasma levels of cocaine, and the impact of these levels on the expression of maternal caregiving behaviors. From these data, we have discovered new dangers in the realm of low doses of cocaine, which have high incentive salience and a surprising impact on maternal caregiving.

Postpartum female rats readily develop a CPP to cocaine after only two to four conditioning doses, suggesting that even in the acute initial exposures, cocaine has significant incentive salience during the postpartum period. Our first CPP studies used cocaine doses yielding plasma levels of cocaine in the 200- to $850-\mathrm{ng} / \mathrm{ml}$ range, levels also common for cocaine-dependent humans, which in rats eliminates all aspects of maternal caregiving (Vernotica et al., 1996; Vernotica and Morrell, 1998). While these doses undoubtedly established a CPP for cocaine, this effect was not as robust as we had expected, and so we began a systematic dose-response exploration of the cocaine CPP task. We discovered that we were using too high a dose of cocaine to find the most robust cocaine CPP. Our dose-response examination of cocaine-induced CPP in postpartum females (Seip et al., 2008) demonstrated that the incentive salience of cocaine varies in a parabolic dose-response curve across a plasma level of 25-400 ng/ $\mathrm{ml}$ of cocaine $(0.5-20 \mathrm{mg} / \mathrm{kg}$, injected) with the peak of $80-90 \%$ of postpartum females developing a strong and lasting CPP for low plasma levels of $40-120 \mathrm{ng} / \mathrm{ml}(1-5 \mathrm{mg} /$ $\mathrm{kg}$ injected). Human users also report initial positive subjective responses with cocaine doses as low as $45-120 \mathrm{ng} / \mathrm{ml}$. To be sure, these positive subjective responses strengthen as cocaine levels rise over $200 \mathrm{ng} /$ $\mathrm{ml}$ in the drug-experienced human subjects, and the stronger salience of higher doses may be influenced by their prior drug history (Kouri et al., 2000; Mendelson et al., 2003; Collins et al., 2007). Nonetheless, the salience of the lower doses in humans and their significant salience in drug naïve rats suggest that such low doses may have significance previously unnoted.

Examining the impact of these low doses of cocaine in independent groups, we found that a plasma level of $120 \mathrm{ng} / \mathrm{ml}$ cocaine ( $5 \mathrm{mg} / \mathrm{kg}$ injected) derailed all aspects of maternal behavior in a manner indistinguishable from the effects of doses in the 400- to $850-\mathrm{ng} / \mathrm{ml}$ range of our earliest studies (Vernotica et al., 1996; Basso and Morrell, in preparation; Pereira and Morrell, in preparation; Figure 1C). The effects of even lower doses of cocaine, $15-40 \mathrm{ng} / \mathrm{ml}$ plasma level, however, were remarkably different in that there was no decrease in pup retrievals or nest building, but there was a remarkable and statistically significant increase, appearing almost obsessive, in the number of anogenital and corporal licks directed at the pups (Figure 1C). This increase in licking is similar to that seen with lower doses of dopamine agonists (Pereira and Morrell, in preparation) and is considerably beyond the natural variation of licking in our controls and even levels in "high-licking" females found among the natural distribution in normal postpartum females (Champagne et al., $2003,2004)$. Since naturally occurring variations in licking frequency have been reported to result in changes in the offspring via epigenetic processes (Weaver et al., 2004), we posit that these cocaine-induced increases in licking to remarkable levels never seen in the natural state should be considered as a form of derailment of maternal behavior, and therefore should be viewed with concern as to the potential changes these patterns might induce in the offspring. 
A

B
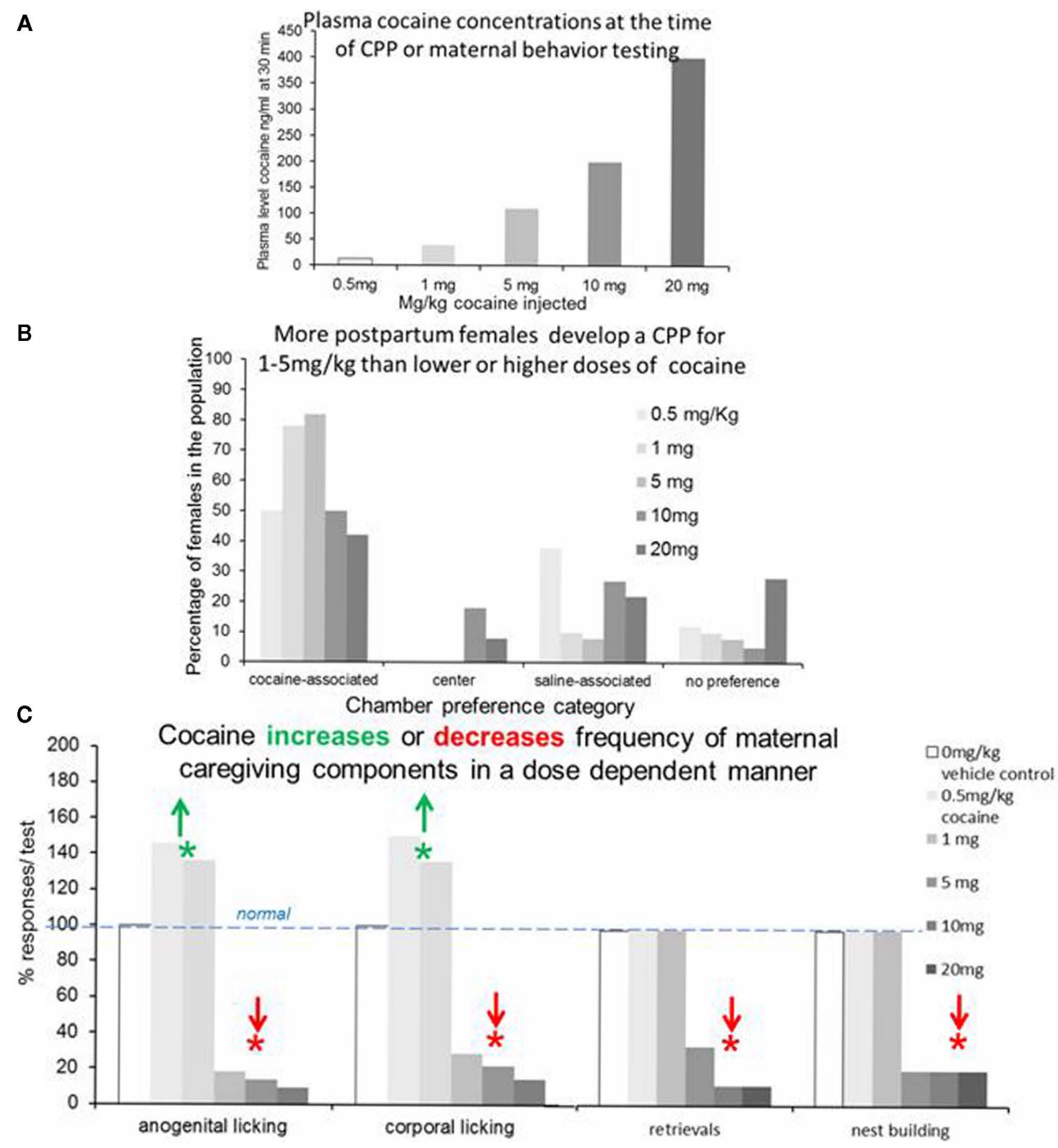

More postpartum females develop a CPP for
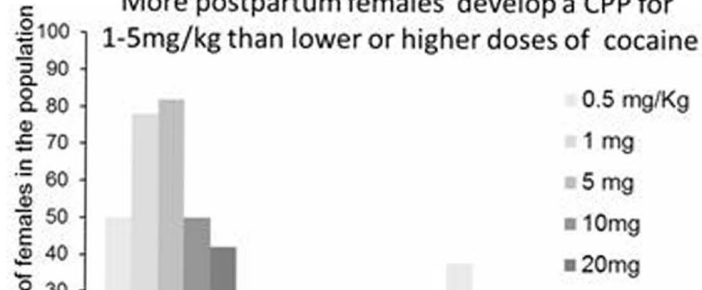

巴ٓ 20

20
10
0

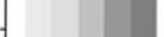

chaine-associated center
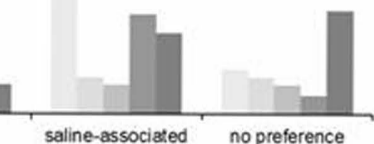


\section{REFERENCES}

Berridge, K. C. (2004). Motivation concepts in behavioral neuroscience. Physiol. Behav. 81, 179-209.

Berridge, K. C. (2007). The debate over dopamine's role in reward: the case for incentive salience. Psychopharmacology (Berl.) 191, 391-431.

Champagne, F. A., Chretien, P., Stevenson, C. W., Zhang, T.Y., Gratton, A., and Meaney, M. J. (2004). Variations in nucleus accumbens dopamine associated with individual differences in maternal behavior in rat. $J$. Neurosci. 24, 4123-4113.

Champagne, F. A., Frances, D. D., Mar, A., and Meaney, M. J. (2003). Variations in maternal care in the rat as mediating influence for the effects of environment on development. Physiol. Behav. 79, 359-371.

Chasnoff, I. J. (1987). Perinatal effects of drugs of abuse. Fed. Proc. 46, 2446-2453.

Chasnoff, I. J. (1988). Drugs, Alcohol, Pregnancy, and Parenting. Boston: Kluwer Academic Publishers.

Collins, S. L., Evans, S. M., Foltin, R. W., and Haney, M. (2007). Intranasal cocaine in humans: effects of sex and menstrual cycle. Pharmacol. Biochem. Behav. 86, 117-124.

Epstein, D. H., Preston, K. L., Stewart, J., and Shaham, Y. (2006). Toward a model of drug relapse: an assessment of the validity of the reinstatement procedure. Psychopharmacology (Berl.) 189, 1-6.

Frank, D. A., Zuckerman, B. S., Amaro, H., Aboagye, K., Bauchner, H., Cabral, H., Fried, L., Hingson, R., Kayne, H., and Levenson, S.M. (1988). Cocaine use during pregnancy: prevalence and correlates. Pediatrics 82, 888-895.

Gawin, F. H. (1991). Cocaine addiction: psychology and neurophysiology. Science 251, 1580-1586.

Javaid, J.I., Fischman, M.W., Schuster, C. R., Dekirmenjian, H., and David, J. M. (1978). Cocaine plasma concentration: relation to physiological and subjective effects in humans. Science 202, 227-228.

Johns, J. M., Elliott, D. L, Hofler, V.E., Joyner, P. W., McMurray, M. S., Jarrett, T. M., Haslup, A. M., Middleton, C. L., Elliott, J. C., and Walker, C. H. (2005). Cocaine treatment and prenatal environment interact to disrupt intergenerational maternal behavior in rats. Behav. Neurosci. 119, 1605-1618.

Johns, J. M, Nelson, C. J, Meter, K. E, Lubin, D. A, Couch, C. D, Ayers, A. A, and Walker, C. H. (1998). Dosedependent effects of multiple acute cocaine injections on maternal behavior and aggression in SpragueDawley rats. Dev. Neurosci. 20, 525-532.

Johns, J. M., Noonan, L. R., Zimmerman, L. I., Li, L., and Pedersen, C. A. (1994). Effects of chronic and acute cocaine treatment on maternal behavior and aggression. Behav. Neurosci. 108, 107-112.

Kinsley, C. H., Turco, D., Bauer, A., Beverly, M., Wellman, J., and Graham,A. (1994). Cocaine alters the onset and maintenance of maternal behavior in the lactating rat. Pharmacol. Biochem. Behav. 47, 857-864.

Kouri, E. M., Martinez Raga, J., McNeil, J. F., and Lukas, S. E. (2000). Impact of family history of alcoholism on cocaine-induced subjective needs and pharmacokinetic profile. Psychopharmacology (Berl.) 152, 268-274.

Lonstein, J. S., and Morrell, J. I. (2007). "Neuroendocrinology and neurochemistry of maternal motivation and behavior," in Behavioral Neurochemistry, Neuroendocrinology, and Molecular Neurobiology. Handbook of neurochemistry and molecular neurobiology (Series edited by Abel Lajtha), 3rd Edn, ed. J. Blaustein (New York, NY: Springer), 2-51.

Mattson, B. J., and Morrell, J. I. (2005). Preference for cocaine- versus pup-conditioned contexts differentially engages neurons expressing either Fos or CART in lactating, maternal rodents. Neuroscience 135, 315-328.

Mattson, B. J., Williams, S., Rosenblatt, J. S., and Morrell, J. I. (2001). Comparison of two positive reinforcing stimuli: pups and cocaine throughout the postpartum period. Behav. Neurosci. 115, 683-694.

Mattson, B. J., Williams, S., Rosenblatt, J.S., and Morrell, J.I. (2003). Preferences for cocaine- or pup-associated chambers differentiates otherwise behaviorally identical postpartum maternal rats. Psychopharmacology (Berl.) 167, 1-8.

McMurray, M. S., Joyner, P. W., Middleton, C. L., Jarrett, T. M., Elliott, D. L., Black, M. C., Hofler, V. E., Walker, C.H., and Johns, J.M. (2008). Intergenerational effects of cocaine on maternal aggressive behavior and brain oxytocin in rat dams. Stress $11,398-410$.

Mendelson, J. H., Sholar, M. B., Mutschler, N. H., JaszynaGasior, M., Goletiani, N. V., Siegel, A. J., and Mello, N. K. (2003). Effects of intravenous cocaine and cigarette smoking on luteinizing hormone, testosterone, and prolactin in men. J. Pharmcol. Exp. Ther. 307, 339-348.

Numan, M., and Insel, T. R. (2003). The Neurobiology of Parental Behavior. New York: Springer-Verlag.

O’Brien, M.S., and Anthony, J.C. (2005). Risk of becoming cocaine dependent: epidemiological estimates for the United States, 2000-2001. Neuropsychopharmacology 30, 1006-1018.

Oro, A. S., and Dixon, S. D. (1987). Perinatal cocaine and methamphetamine exposure: maternal and neonatal correlates. J. Pediatr. 111, 571-578.

Pereira, M., and Morrell, J. I. (2010a). The medial preoptic area is necessary for maternally motivated choice of pup but not cocaine-associated environments in postpartum rats. Neuroscience 167, 216-231.

Pereira, M., and Morrell, J. I. (2010b). "Differential effects of discrete subarea-specific transient inactivation of the medial prefrontal cortex on the motivated choice of pup- versus cocaine-associated environments by early postpartum rats," in Abstract, Society for Neuroscience, San Diego, CA.

Pereira, M., Seip, K., and Morrell, J. I. (2008). "Maternal motivation and its neural substrate across the postpartum period," in Neurobiology of the Parental Brain, ed. R. Bridges (Burlington, MA: Academic Press), 39-60.

Rosenblatt, J. S., Siegel, H. I., and Mayer, A. D. (1979). Progress in the study of maternal behavior in the rat: hormonal, nonhormonal, sensory, and developmental aspects. Adv. Study Behav. 10, 225-311.

Seip, K. M., and Morrell, J. I. (2007). Increasing the incentive salience of cocaine challenges preference for pup- over cocaine-associated stimuli during early postpartum: dual-choice conditioned place preference and locomotor analyses. Psychopharmacology (Berl.) 194, 309-319.

Seip, K. M., and Morrell, J. I. (2009). Transient inactivation of the ventral tegmental area selectively disrupts the expression of conditioned place preference for pup- but not cocaine-paired contexts. Behav. Neurosci. 123, 1325-1338.

Seip, K. M., Pereira, M., Wansaw, M. P., Dziopa, E. I., Reiss, J. I., and Morrell, J. I. (2008). Incentive salience of cocaine is remarkably stable across postpartum in the lactating female rat: route of administration and dose manipulations using place preference. Psychopharmacology (Berl.) 199, 119-130.

Smith, R. F., Mathran, K. M., Kurkjian, M. F., and Kurtz, S. L. (1989). Alterations in offspring behavior induced by chronic prenatal cocaine dosing. Neurotoxicol. Teratol. 11, 31-48.

SubstanceAbuse, and MentalHealth Services Administration (SAMHSA) (2001-2003). Office of Applied Studies, National Survey on Drug Use and Health. Rockville MD: NHSDA Series H-13-15 DHHS Publication.

Tzschentke, T.M. (2007). Measuring reward with the conditioned place preference paradigm (CPP): update of the last decade. Addict. Biol. 12, 227-462.

Vernotica, E., Lisciotto, C. A., Rosenblatt, J. S., and Morrell, J. I. (1996). Cocaine impairs maternal behavior: a rodent model. Behav. Neurosci. 110, 315-323.

Vernotica, E. M., and Morrell, J. I. (1998). Plasma cocaine levels and locomotor activity after systemic injection in virgin and in lactating maternal female rats. Physiol. Behav. 64, 399-407.

Wansaw, M. P., Lin, S.-N., and Morrell, J. I. (2005). Plasma cocaine levels, metabolites, and locomotor activity after subcutaneous cocaine injection are stable across the postpartum period in rats. Pharmacol. Biochem. Behav. 82, 55-66.

Warner, L. A., Kessler, R. C., Hughers, M., and Anthony, J. C. (1995). Prevalence and correlates of drug use and dependence in the United States. Arch. Gen. Psychiatry 52, 219-229.

Weaver, I.C. G., Cervoni, N., Champagne, F.A., D’Alessio, A. C., Sharma, S., Seckl, J. R., Dymov, S., Szyf, M., and Meaney, M. (2004). Epigentic programming by maternal behavior. Nat. Neurosci. 7, 847-854.

Zimmerberg, B., and Gray, M. S. (1992). The effects of cocaine on maternal behavior in the rat. Physiol. Behav. 52, 379-384.

Received: 18 April 2011; accepted: 16 May 2011; published online: 30 May 2011.

Citation: Morrell JI, Basso JC and Pereira M (2011) Both high and low doses of cocaine derail normal maternal caregiving - lessons from the laboratory rat. Front. Psychiatry 2:30. doi: 10.3389/fpsyt.2011.00030

This article was submitted to Frontiers in Child and Neurodevelopmental Psychiatry, a specialty of Frontiers in Psychiatry.

Copyright $\odot 2011$ Morrell, Basso and Pereira. This is an open-access article subject to a non-exclusive license between the authors and Frontiers Media SA, which permits use, distribution and reproduction in other forums, provided the original authors and source are credited and other Frontiers conditions are complied with. 